\title{
“Nunca pensei sobre isso!": vivências de trabalho na indústria metalmecânica
}

\author{
Maristela Rancan, Carmem Regina Giongo \\ Universidade Feevale (Novo Hamburgo, RS, Brasil)
}

\begin{abstract}
É de fundamental importância entender as relações existentes entre o trabalho e os processos de saúde/doença mental, visando ao desenvolvimento de ações de prevenção e promoção da saúde do trabalhador. Diante da escassez de estudos que privilegiem esse aspecto entre os trabalhadores que atuam na indústria metalmecânica no Brasil, esta pesquisa tem o objetivo de analisar as vivências de trabalho de profissionais inseridos no contexto metalmecânico para compreender a dinâmica saúde/doença mental no trabalho. Através de um delineamento exploratório-descritivo, a pesquisa foi orientada teoricamente pela Psicodinâmica do Trabalho. Foram entrevistados individualmente oito trabalhadores da indústria metalmecânica da região de Caxias do Sul (RS), com idades entre 20 e 54 anos. Como instrumentos de coleta de dados foram utilizados um questionário sociodemográfico e entrevista semiestruturada. Os dados foram examinados por análise de conteúdo. Os resultados apontaram claramente para o intenso processo de sofrimento e para o grande risco de adoecimento dos trabalhadores entrevistados, evidenciando a necessidade de problematizar e repensar as relações e a configuração do trabalho metalmecânico.
\end{abstract}

Palavras-chave: Psicodinâmica do trabalho, Sofrimento, Saúde mental, Metalúrgicos, Psicologia do trabalho.

"I have never thought about it!": work experiences in metalworking industries

It is essential to understand the existing relations between labor and mental health/disease processes, considering the development of preventive actions and promotion of the employees' health. Due to the lack of studies focusing in this aspect among employees from metalworking industries in Brazil, this study aims to analyze the work experiences of professionals who are part of the metalworking context, aiming at understanding the mental health/disease dynamic at work. Through an exploratory-descriptive design, the research was theoretically oriented by the Psychodynamics of Work. Eight employees (ranging from 20 to 54 years old) from the metalworking industry in Caxias do Sul (Rio Grande do Sul, Brazil), were individually interviewed. A social-demographic questionnaire and a semi-structured interview were used as data gathering instruments. Data were analyzed through content analysis. Results clearly implied the existence of an intense suffering process and a considerable risk of illness in the interviewed employees, which demonstrated the need to problematize and rethink the relations and the configuration of the metalworking work.

Keywords: Psychodynamics of work, Suffering, Mental health, Metallurgy workers, Work psychology.

\section{Introdução}

A atividade industrial no Brasil teve início no período colonial. O processo de industrialização Mundial. Com a Segunda Guerra Mundial, o ritmo de industrialização intensificou-se e a indústria começou a ter destaque econômico (Herédia, 2007), e atualmente o segmento industrial é um dos principais no país. A indústria metalúrgica, considerando-se o cenário nacional, tem grande representatividade econômica, o que pode ser observado com base no Produto Interno Bruto (PIB), importante indicador da macroeconomia. Segundo o Anuário Estatístico do Setor Metalúrgico divulgado em 2013, considerando o ano-base 2012, o PIB setorial foi de US\$ 51,5 bilhões, o que representa 2,3\% do PIB nacional e 8,5\% do PIB industrial (Ministério do Trabalho e Emprego, 2013). Isso mostra a relevância do segmento e a sua importante contribuição para o desenvolvimento do Brasil.

De acordo com dados do Ministério do Trabalho e Emprego, até julho de 2014 foram registrados 2.412.342 trabalhadores atuantes no ramo metalúrgico no Brasil. Porém, o momento é de preocupação para o setor, pois se estima que nos seis primeiros meses de 2014 mais de 21,8 mil postos de trabalho tenham sido fechados. Esse cenário difere da realidade do mês de junho de 2013, quando mais de 1,5 mil postos de trabalho estavam sendo gerados. 
O desenvolvimento da indústria no Rio Grande do Sul acompanhou o que estava acontecendo no restante do país. A primeira siderúrgica surgiu em 1948 e serviu de base estrutural para a expansão do segmento. Assim, as atividades econômicas associadas à primeira siderúrgica fomentaram o crescimento econômico de algumas regiões, como a metropolitana de Porto Alegre, o Nordeste do Estado, com Caxias do Sul centralizando o polo metalmecânico regional, e a região Noroeste, com elevada produção de tratores e máquinas agrícolas (Guaraná, 2006).

Segundo dados do Instituto Brasileiro de Geografia e Estatística (IBGE), Caxias do Sul é o segundo município mais populoso do Estado do Rio Grande do Sul, com 470.233 habitantes em 1을 de julho de 2014. A cidade é considerada o segundo polo metalmecânico do país e um dos maiores da América Latina, respondendo por cerca de 5,83\% do PIB do Rio Grande do Sul (Instituto Brasileiro de Geografia e Estatística, 2014).

A história da indústria em Caxias do Sul se iniciou com a chegada dos imigrantes italianos em 1875. Eles trouxeram consigo a forte valorização do trabalho, o sentimento religioso, o valor à propriedade familiar e a certeza de que seriam vitoriosos. Esse povo tornou a atividade agrícola sua forma de subsistência, e a região transformou-se na sede da colonização italiana no Rio Grande do Sul. Além de conhecimentos relativos à agricultura, os imigrantes trouxeram várias técnicas que levaram ao desenvolvimento de atividades artesanais e industriais. Assim, rapidamente a região se desenvolveu.

Muitas indústrias caxienses nasceram da evolução da unidade artesanal e passaram de empresas fabril-manufatureiras ou de pequenas empresas de origem familiar para grandes fábricas. Dessa forma, todo o processo de surgimento das indústrias ocorreu de forma gradual e se consolidou a partir do momento em que essas empresas se firmavam no mercado nacional. A comprovação desse avanço pode ser percebida até os dias atuais, com o grande número de indústrias em funcionamento na região, resultado de muito trabalho e de forte espírito empreendedor (Herédia, 2007).

Do ponto de vista da saúde do trabalhador, um dos aspectos que historicamente caracterizam o trabalho nesse segmento são os elevados riscos à saúde física dos profissionais. Estudos realizados nos últimos anos têm associado as formas de adoecimento e de acidentes de trabalho aos modos de gestão e de produção característicos da indústria metalmecânica (Picoloto \& Silveira, 2008; Gonçalves \& Dias, 2011), apontando para a necessidade de aprofundar o entendimento dos processos de saúde e adoecimento nesse contexto.

Uma abordagem possível para essa análise é a Psicodinâmica do Trabalho, que surgiu em 1980 a partir dos estudos de Christophe Dejours e que, atualmente, busca compreender como os trabalhadores subjetivam as vivências, qual o sentido elas assumem e quais as estratégias coletivas utilizadas para dar conta do que é ocasionado pela organização do trabalho (Mendes, 2007). Na análise do processo de saúde e adoecimento, um dos elementos principais é a compreensão da dinâmica prazer/sofrimento, bem como das estratégias defensivas diante dos fatores da organização do trabalho (Dejours, 2011). Assim, podem existir situações em que o trabalho seja, ao mesmo tempo, fonte de prazer e de sofrimento, transformando-se em contradição. De acordo com Mendes e Morrone (2010), essa contradição é um movimento psíquico que busca constantemente o prazer e evita o sofrimento, o que implica na busca de equilíbrio. Essa dinâmica de buscar o prazer para evitar o sofrimento é responsável pela saúde psíquica, mas o sofrimento, por si só, não pode ser considerado patológico porque funciona como um sinal de alerta para evitar o adoecimento por meio da utilização de estratégias defensivas (Martins, 2012).

As estratégias defensivas visam à adaptação do sujeito às pressões de trabalho e podem ter características individuais ou coletivas, buscando a promoção da resistência psíquica diante de determinadas formas de organização do trabalho (Martins, 2012). Elas são mecanismos utilizados pelos trabalhadores para diminuir a percepção da realidade causadora de sofrimento, e por isso 
sua utilização é uma das formas de enfrentamento do sofrimento. Além disso, essas estratégias têm caráter positivo, pois colaboram com a adaptação dos sujeitos à sua realidade profissional, visando ao equilíbrio psíquico. Em contrapartida, em algumas situações essas estratégias encobrem o sofrimento psíquico passando a adquirir condição patológica (Mendes \& Morrone, 2010). Sendo assim, as estratégias defensivas não necessariamente são caracterizadas por luta ou transformação, mas por adaptação do trabalhador ao sofrimento, o que pode, com o passar do tempo, desencadear o adoecimento.

O equilíbrio entre prazer e sofrimento dependerá da margem de liberdade que é oferecida aos profissionais e da qualidade da dinâmica do reconhecimento da contribuição individual que o sujeito dará à organização do trabalho. Se a realidade do trabalho não permite a utilização de estratégias defensivas, o sofrimento efetivamente pode ser vivenciado, potencializando o adoecimento (Mendes \& Morrone, 2010). Nesse sentido, o desenvolvimento de estudos e intervenções no campo dos processos de saúde e adoecimento torna-se fundamental para a compreensão das interações entre trabalho e saúde. Buscando contribuir com o entendimento dessa dinâmica no campo do trabalho metalmecânico, este estudo objetiva compreender os processos de saúde/doença no trabalho em indivíduos que atuam no ramo metalmecânico a partir de suas vivências. Para isso, analisaram-se as vivências de prazer e sofrimento dos trabalhadores, bem como as estratégias defensivas utilizadas por eles.

\section{Metodologia}

Este estudo possui delineamento qualitativo exploratório-descritivo. É exploratório na medida em que se propõe a buscar maior familiaridade com o tema pesquisado, e é descritivo por descrever as características do grupo de trabalhadores investigado (Gil, 2010). Para a coleta de dados foram entrevistados oito trabalhadores da indústria metalmecânica da região de Caxias do Sul, dos quais 7 eram do sexo masculino e 1 do feminino, com idades entre 20 e 54 anos (M: 39,3; DP: 13,20$)$ e com tempo médio de 11,6 anos de empresa. Quatro participantes possuíam ensino médio completo, dois possuíam o ensino médio incompleto, um possuía ensino fundamental completo e um possuía o ensino superior em andamento. A renda média dos participantes era de dois a três salários mínimos para quatro participantes e de cinco salários mínimos para os outros quatro participantes.

A seleção dos entrevistados foi realizada através da técnica de snow ball, processo pelo qual os primeiros participantes indicam os demais de forma sucessiva (Biernacki \& Waldorf, 1981). Como instrumento de coleta de dados foi aplicado questionário sociodemográfico para levantar dados que caracterizassem os participantes e a sua relação formal com o trabalho. $O$ questionário foi composto por itens como idade, sexo, escolaridade e características formais da relação com o trabalho e com a profissão - como tempo de empresa, cargo, carga horária mensal, intervalos, horas extras, renda e realização de outras atividades para complementar a renda -, bem como por dados sobre a possível ocorrência de lesões e acidentes decorrentes do trabalho. Também foi utilizada a técnica de entrevista semiestruturada com o intuito de compreender as vivências de prazer e de sofrimento e as estratégias coletivas de defesa. $\mathrm{O}$ roteiro da entrevista foi composto por perguntas-estímulo, que direcionaram o pesquisador para o começo da exploração do tema da pesquisa, e seguiu as orientações de Mendes (2007). A coleta de dados ocorreu individualmente após contato telefônico do pesquisador e aceite de participação do trabalhador. Todos os entrevistados assinaram o Termo de Consentimento Livre e Esclarecido. As entrevistas foram gravadas em áudio e cada uma teve duração média de quarenta minutos. Este estudo seguiu as diretrizes da Resolução 
016/2000 do Conselho Federal de Psicologia (2000) e da Resolução 196/96 do Conselho Nacional de Saúde (Brasil, 1996).

O material coletado, gravado em áudio e transcrito na íntegra, foi analisado conforme análise de conteúdo proposta por Bardin (2011). Essa análise é composta pelas seguintes etapas: pré-análise, exploração do material e tratamento dos resultados. As informações coletadas por meio do questionário sociodemográfico foram analisadas de maneira descritiva.

Para a análise interpretativa, buscaram-se, ao longo dos relatos, significados para as categorias estabelecidas a priori: "'Então as horas passam e a sua produção não sai': as vivências de sofrimento"; "'Acho que, quando é pra ser, vai ser': as estratégias defensivas"; "'Eu me sinto satisfeito, eu me sinto assim!': vivências de prazer". Essas categorias tiveram origem na abordagem teórica utilizada e, portanto, remetem ao roteiro da entrevista. Em contrapartida, a categoria estabelecida a posteriori aborda temática que não estava prevista e que surgiu ao longo das entrevistas. Essa categoria foi nomeada como "Possibilidades de transformação: o papel da Psicologia". Cabe salientar que no texto os participantes foram identificados por nomes fictícios, escolhidos por eles próprios. Além disso, destaca-se que a interpretação realizada acerca do sofrimento é indireta e interpretativa, aproximando a escuta analítica do discurso dos sujeitos.

\section{Análise e discussão dos resultados}

O ser humano torna-se ser social por meio do ato de produção e reprodução de sua própria existência; ao produzir, ele passa a se distinguir de todas as formas não humanas, e, através de sua cotidianidade, constrói sua identidade. Observa-se que os dados coletados através deste estudo, além de contribuírem para a elucidação do processo de saúde e adoecimento no trabalho metalmecânico, trazem importantes reflexões acerca das estratégias utilizadas pelo capital para distorcer o sentido do trabalho e transformar os sujeitos em mercadorias que produzem mercadorias, destituindo a possibilidade de realização no trabalho e privando o trabalhador de se perceber na atividade profissional (Antunes, 2005).

\section{"Então as horas passam e a sua produção não sai”: vivências de sofrimento}

O trabalho pode ser entendido como aquilo que implica o ato de trabalhar. No modo de trabalhar, encontram-se os gestos, o saber-fazer, o engajamento do corpo, a mobilização da inteligência, a capacidade de refletir, de interpretar e de reagir às situações e o poder de sentir, pensar e inventar (Dejours, 2004b). Um dos pontos investigados nesta pesquisa foram os sentimentos acerca do trabalho metalmecânico; foram comuns expressões como a de MX.: "Bah! Agora tu me pegou! Nunca pensei sobre isso!”. A partir dessa fala, a primeira observação a ser feita é que a manifestação do sofrimento parece estar inviabilizada pela organização do trabalho em análise. O discurso está esvaziado e, para os trabalhadores, suas rotinas, tarefas e necessidades estão de acordo com as normas de cada instituição. Para Mendes e Merlo (2009), a normalidade é o resultado do compromisso entre o sofrimento e as estratégias de defesa individuais ou coletivas que se organizam para manter a saúde. Observe-se a fala de MC:

Ah, meu trabalho, na verdade, tem que gostar, né? Tem que gostar, porque assim, ó, o inverno, ele é até bom pra trabalhar; no verão, ele é sofrido, ele é pesado, ele é sujo, ele causa muitos malefícios à saúde... Fumaça, até o próprio raio de solda, que é cancerígeno... Então tem que se gostar do que se 
faz, senão não aguenta! E o que eu faço eu gosto, entende? Faz um monte de tempo que eu tô nisso aí e eu gosto, mesmo que seja sofrido, sujo... Mas tem que fazer, né?! (MC.).

O sofrimento é uma experiência vivenciada, um estado mental que implica reflexão do sujeito sobre seu "estar no mundo", mas essa vivência não é totalmente consciente, pois sempre existe uma parte que não pode ser apreendida e que está indissociável da corporalidade. Assim, o sofrimento é do corpo que está entrelaçado no mundo e nas relações com os outros (Dejours, 2007), e surge quando a negociação entre o sujeito e a realidade imposta se torna inviável, podendo o sofrimento se intensificar na medida em que a organização impede que os sujeitos utilizem sua inteligência prática, subvertendo o trabalho real (Mendes, 2007). $O$ ato de trabalhar não pode ser tratado apenas como meio de produção, mas como atividade que transforma a subjetividade e o próprio sujeito (Dejours, 2004a). Os discursos dos entrevistados não demonstram claramente as inseguranças e insatisfações relacionadas ao trabalho, mas elas ganham espaço quando observadas nos relatos sobre os sentimentos relacionados ao trabalho.

Quando eu chego na empresa, tenho o sentimento de que um dia vai parar, né?, um dia eu vou sair da empresa. E outra que o cara acostuma, é 20 anos que eu tô lá, então se não é bom tu não ficaria 20 anos no mesmo lugar, né?, não dá nem pro cara prever o que vai acontecer, o que tu vai fazer depois, né? Isso não me assusta... O cara faz, ó... O cara tá se programando há um tempo pra isso, né?, então ... Às vezes, o cara conversa com um, conversa com outro, né?, 20 anos... Os outros colegas que ficam aí chegam em 27, 28, a 30, 25... Então tá chegando (D.).

A fala de D. exemplifica o que Ferreira (2009) comenta sobre a organização do trabalho, ao dizer que ela sempre terá alcance na subjetividade, nas relações interpessoais e na rede subjetiva, que é mobilizada pelas relações de trabalho. Dejours e Abdouchelli (2011) explicam que o sofrimento implica estado de luta do sujeito contra as forças da organização do trabalho que o movem em direção à doença mental.

Eu me sinto bem de fazer, chegar no final do dia e ter feito a minha obrigação, né?, ter feito, de passou o dia e eu fiz minha obrigação, eu fiz meu rendimento, minha parte, né? Então você vai pra casa tranquilo, porque eu deixei minha parte lá. Eu não me sinto bem, às vezes, quando eu saio, e tem dias que não dá muito bem, né?, por algum problema e tal, né?, então as horas passam e a sua produção não sai... Aí você fala, né? Isso vai aparecer lá no índice, né?, e aí vai aparecer lá, né? Então, claro que isso desmotiva e tudo mais, né?, mas sempre, né?, é bom, sempre sair da empresa... E, quando você chega na empresa, começar um dia bom e sair de lá com ele completo, né? Aí é gratificante, né? (R.).

As pressões e cobranças exercidas pela organização do trabalho demandam dos trabalhadores muita energia psíquica. Mendes e Merlo (2009) afirmam que a saúde, para a Psicodinâmica do Trabalho, encontra-se entre a patologia e a normalidade e é resultado de como os trabalhadores agem diante do sofrimento imposto pela organização do trabalho. Os trabalhadores falam sobre o momento em que saem da empresa, e o discurso se apresenta pelo alívio das pressões, dos controles e das normas.

Ah! Vamo descansar agora, chegar em casa e dormir, mas nada como "bah, que alívio sair de lá...” (MT.). 
Quando eu saio? Vou descansar... (risos) É, ah, bah, terminou o dia... Bah, então vamo descansar agora... Descansar, e não, ahn, digo assim, sair pra boteco ou coisa assim, né? Eu já procuro descansar pra, no outro dia, já vir descansado, né? (J.).

Sinto... mais um dia que passou, né? Tô vindo pra casa descansar, pra ir de novo no outro dia, né? (D.).

Por essas falas, é possível perceber a existência do esvaziamento. Os trabalhadores estão tão automatizados pelos processos de trabalho que executam, que há sentimento de tristeza e, como não há reflexão, nem eles mesmos sabem do que estão sofrendo, nem eles mesmos sabem o que poderia ser transformado - são falas apáticas e até despersonalizadas. Dejours (1992) afirma que o sofrimento ganha espaço para emergir quando o ser humano não consegue mais modificar suas tarefas conforme suas necessidades e seus desejos, pois, a parir desse elemento, o trabalho deixa de oferecer condições para a estruturação do psiquismo e não encontra mais possibilidade de vivência de prazer.

Dificuldades? Olha, acho que nenhuma... A dificuldade é a pessoa que faz... Porque eu aprendi uma coisa - que não existe a palavra "não dá pra fazer", não existe! Sempre tem um jeito. É só a gente parar e analisar, que sempre tem um jeito! (C.).

O sofrimento não existe, pois ele nem sequer consegue ser problematizado. As dificuldades encontradas pelos trabalhadores são relacionadas à atividade em si, ao que está prescrito. $\mathrm{O}$ toyotismo torna a exploração do capital mais consensual, envolvente e manipulatória (Alves, 2008), porque a organização de trabalho utiliza mecanismos de controle e de submissão dos trabalhadores. A submissão aparece como forma de sofrimento, pois é questionada por um dos participantes, Max, que relatou que precisava realizar as atividades conforme era orientado a executá-las, mesmo não concordando com a forma como seu coordenador queria que fossem realizadas, porque não havia espaço para o questionamento. Ele relatou, ainda, demonstrando sofrimento, o motivo que causou seu desligamento da empresa.

Aí, então, chegou na sextafeira, e aí... Eu até ia viajar... Aí, eu cheguei e daí eu pedi pro meu chefe, né?, eu tinha falado pra ele isso, tipo, na quarta-feira, que eu tava sem o cartão, aí, pra eles pagarem em dinheiro, né?, daí eles faziam isso aí... Aí, ele disse "tá, eu vou falar pra ela...”, pra dona, né? Aí, chegou na sexta e eu pedi se ele tinha falado com ela, e ele disse que não tinha falado com ela, e eu disse "tá, e como eu vou fazer com meu dinheiro?", e ele "ah, agora é só segundafeira...", e eu disse "não, então só vou assinar a folha quando eu receber...”. Aí, ele ficou bravo comigo, aí começamos a discutir e não sei o quê... Aí, eu falei "não, não tem por que eu assinar...". Eu ia assinar a folha só na segunda-feira. "Se eu vou receber só na segunda, vou assinar só na segunda...”. Aí, ele ficou bravo comigo, aí... (MX.).

MX. relatou com riqueza de detalhes as condições de submissão que a organização do trabalho estava lhe impondo. Não era permitido sequer questionar se seu salário seria pago conforme o previsto na legislação. Quando questionou, a empresa o demitiu, apresentando como argumento de que não estava mais rendendo o necessário para a função. Max ainda relatou o seguinte:

Na outra semana, tinha o feriado, né?... Aí, eles me deram a folha de hora extra e eu marquei os dias que podia fazer, aí, segunda-feira, eu coloquei que eu ia, na terça, que eu ia, quarta-feira, eu ia... Aí, na quinta, eu disse que não ia e não coloquei, porque... Daí, na sexta, coloquei que não ia... Daí, no sábado, eu coloquei que não ia, porque era feriado. Aí, na segunda-feira, tava a carta em cima da mesa... Daí, até, tipo, depois me desleixei... Tipo, fiquei bem de boa, que nem diz o outro, já que não 
queriam que eu trabalhasse lá, então fiquei jogado, tipo, fazia quando dava... Também não deixava a desejar, mas fazia o que dava (MX.).

No momento da demissão, o trabalhador precisou cumprir os trinta dias do aviso prévio imposto pela empresa. A partir da vivência de MX., aparecem as formas de punição que as empresas utilizam para "regrar os corpos". Essas estratégias fazem que os trabalhadores sejam expostos e até mesmo ridicularizados em algumas situações. Quando a organização do trabalho não pode mais ser transformada, o sofrimento começa a ser percebido, pois a energia pulsional, que não acha descarga no exercício do trabalho, se acumula no aparelho psíquico, ocasionando sentimentos de desprazer e tensão (Dejours, 2007).

6 horas saía de casa, 6 horas... Acordava 5:30, isso quando era horário normal. Eles cobravam bastante serão - hora extra, né? -, cobravam, modo de dizer, a gente não era obrigado... E 3:30 pegava o ônibus, chegava lá 5:10, e começava a trabalhar. 3:30 da manhã é puxado, bem puxado. No inverno era uma maravilha, e a gente começava a trabalhar e... Ah! O clima era bom... Por mais que tinha pressão, assim, mas, tipo, "ah, vamo lá...”, era pressão, mas era mais uma brincadeira, bah! A gente tinha que tirar sarro e "vamo lá, se puxem...", mas, assim, aquele clima tranquilo, né? Nada de... Ah, sempre tem, de 30, 1, 2 não vai gostar, mas a maioria era tranquilo (MT.).

As cobranças excessivas para atingir metas e a pressão exercida pela organização do trabalho surgem no discurso dos sujeitos. As exigências do trabalho acelerado e repetitivo são apresentadas com sofrimento por $\mathrm{V}$, que fala sobre o cansaço que sente quando sai da empresa. Além disso, mesmo cansada, no final do dia, fala sobre a exigência de manter o ritmo estabelecido pela máquina.

Cansaço... Tem dias que chega em casa entregue, cansada... E, ainda, agora tem pouco serviço, mas quando tem muito serviço, é apurado. Que nem quem trabalha na esteira, e a esteira não para, tem que dar conta (V.).

O trabalhador cede ao capital seu potencial, que é comprado por um determinado período (Silva, 2011). V. comenta sua insatisfação em relação ao salário e novamente é possível identificar a busca que o trabalhador realiza para encontrar o reconhecimento no trabalho, mesmo que seja através de reajustes salariais.

Ah! Eu gosto de trabalhar ali, eu gosto do que eu faço, só não gosto do salário, que não dão valor pras pessoas... Que nem, né?, a pessoa que entra agora, entra ganhando a mesma coisa que a gente que tá aí há 20 anos, e, pensa... Isso aí é porque eles não valorizam as pessoas. Sim, a gente fala, mas "vai ver", "vai vim", "vamo ver", mas só que nunca vem (V.).

Contando que a empresa responsabiliza o profissional pela sua remuneração, $\mathrm{MX}$. complementa a questão da falta de valorização financeira:

É, tipo, que nem eles falavam pra mim: "o teu salário quem faz é tu; se tu ficar que nem uns aí, 2 ou 3 anos naquelas, vai, não vai, tu também não ganha aumento...” (MX.).

Observa-se que as relações sociais banalizadas têm repercussão na vida pessoal dos sujeitos. Dejours (2007) afirma que o ser humano como um todo está condicionado ao comportamento estabelecido pela organização do trabalho, dentro e fora dela, e, dessa forma, angústias, medos e pressões não conseguem ficar ausentes do trabalho. 
Eu era mais preocupado com o trabalho, não é que hoje eu não sou preocupado com o trabalho, mas hoje eu sou mais de separar as coisas, né? Venho pra casa, dificilmente falo de trabalho... Minha esposa, minha filha também é muito difícil falar de trabalho... Mas é claro que eu não esqueço, né? Mas não adianta, você trabalha, estressado, o tempo passa, a mesma coisa... Você não trabalhar estressado o tempo vai passar igual, então por que que eu vou me estressar? (R.).

Dejours (2007) distingue as formas de sofrimento, que pode se apresentar como criativo ou como patogênico. $O$ sofrimento patogênico surge quando não existem mais possibilidades de transformação no trabalho, quando o sentimento de incapacidade toma conta do sujeito. A partir do momento em que as ações do trabalho permitem a utilização da criatividade, a transformação do sofrimento é possibilitada e, dessa forma, o trabalho ocupa o lugar de mediador entre saúde e doença.

O sofrimento é concebido então como a vivência subjetiva intermediária entre a doença mental e o bem-estar psíquico. Nas entrevistas realizadas, houve poucas respostas sobre as vivências de sofrimento, o que permite inferir que pode existir esvaziamento de reflexão sobre o sofrimento, que é apresentado com normalidade pelos trabalhadores. É necessário considerar essa normalidade como enigma e entender o que faz que os trabalhadores resistam às pressões psíquicas do trabalho, evitando descompensação ou loucura (Dejours, \& Abdouchelli, 2011). A partir dos relatos dos participantes foi possível perceber que existem poucos espaços que possibilitam a transformação dos fatores de sofrimento apresentados pela organização do trabalho. Assim, os sofrimentos relatados pelos trabalhadores podem se transformar em adoecimento.

\section{"Acho que, quando é pra ser, vai ser": as estratégias defensivas}

O conflito entre a organização do trabalho e o funcionamento psíquico pode ser reconhecido como fonte de sofrimento, mas, ao mesmo tempo, pode se apresentar como instrumento de análise (Dejours, \& Abdouchelli, 2011). Entende-se que, para suportar o sofrimento decorrente da precariedade do trabalho, os trabalhadores utilizam defesas psíquicas. Nesta pesquisa, os entrevistados negam qualquer tipo de dano à sua saúde - isso permite que eles continuem trabalhando. É assim que a organização do trabalho é provedora de todas as necessidades dos sujeitos. Na perspectiva dos entrevistados, a empresa treina, oferece condições de trabalho e dispõe de segurança, e por isso lhe é permitido cobrar e exigir dos trabalhadores toda sua capacidade laboral.

Sim, tu vai numa máquina, eles te dão treinamento. Se a máquina não tá em condições de trabalhar, não tem que trabalhar, não é pra trabalhar. A máquina tem que estar em condições de trabalho e aí vem a exigência. Tu tem que dar o teu lado, né?, mas eles primeiro se preocupam em dar as máximas condições pra gente trabalhar e, depois disso, sim, depois tem a nossa parte, né?! (R.).

O trabalhador alienado das causas de sofrimento não questiona nenhuma característica da organização do trabalho. Modos de pensar, agir e sentir são estratégias defensivas para suportar o sofrimento (Mendes, 2007). Outra estratégia utilizada pelos trabalhadores e observada nos discursos é a hiperaceleração, que, de acordo com Uchida (2007), no trabalho repetitivo ocorre espontaneamente, mesmo quando os trabalhadores podem decidir sobre o ritmo de sua produção, pois, quando deparam com o tédio da repetição da atividade, surge o sofrimento, e os trabalhadores passam a ter consciência de sua condição, ou seja, aumentando a velocidade da tarefa eles podem se concentrar nela e evitar o sofrimento. 
Ah! Eu gosto mais assim: trabalho mais rápido, mas agitado! Se é muito parado, dá muito sono... Daí, quanto mais agitado, melhor (V.).

Essa estratégia apresenta características contraditórias, pois, ao mesmo tempo que protege os trabalhadores, aliena-os. V., ao falar sobre seu trabalho repetitivo, não consegue expressar seu sofrimento nem mesmo relatar como eram ou são suas dores. Nas palavras da entrevistada, são sempre os outros que "começaram a se queixar". As estratégias defensivas permitem aos trabalhadores ignorar a influência da organização do trabalho - assim, ficam subordinados à lógica do capital, o que impossibilita a mudança que poderia levar às vivências de prazer (Ferreira, 2009).

Porque, que nem disse a psicóloga uma vez, a gente... Nós somos pessoas. Máquinas, você vai lá, aperta um botão, você liga, aperta outro, você desliga, mas a cabeça da gente não é assim, não é. Agora, por exemplo, assim, se você tá na empresa, agora só vou pensar na empresa, não tem isso. Você vai pensar, às vezes, alguma coisa em casa, alguma coisa tem, mas tem que sempre procurar focar onde você tá, né? (R.).

A subjetividade está protegida pelas defesas e, dessa forma, as defesas podem evitar que o sujeito tome consciência de sua realidade (Dejours, 2004a). Partindo desse ponto, entendem-se as razões por que as queixas são inexistentes.

Muito bom... O ambiente de trabalho lá é bom. Ah, eu me sinto contente. Olha... Eu tô contente do trabalho que eu faço, me sinto feliz, no caso, né?, e consegui, tudo o que eu tenho é do meu trabalho, né?, da firma, então não tem do que reclamar e nem de se queixar, né? Não tem como tu dizer que não tá bom, né? Acho que é isso (D.).

As estratégias defensivas são mecanismos pelos quais os trabalhadores buscam modificar, transformar e diminuir as percepções da realidade que causam sofrimento. Essa ação é exclusivamente mental e, por isso, geralmente não consegue modificar a realidade da pressão patogênica (Dejours, \& Abdouchelli, 2011).

Ah, marca, tipo, só o lado bom, porque assim tu não vai ficar pensando só o ponto negativo... Tipo, o lado bom é que teve várias amizades e, tipo, nunca briguei com ninguém, nunca discuti com ninguém, e, tipo assim... Não, só com meu chefe... (risos) E, tipo, cada firma que eu entrei, aprendi bastante coisa, nunca me deixaram jogado, assim, sempre me explicaram como é que tem que fazer, e coisa que tu aprende pra vida toda (MX.).

A racionalização é uma defesa de adaptação às situações que causam sofrimento, de forma a evitar o adoecimento por meio da alienação das causas do sofrimento, mas nela não ocorre a tentativa de mudança da organização do trabalho (Dejours, 2004a). Os trabalhadores estão se apropriando da estratégia de racionalização. Segundo Dejours (2007), essa estratégia de defesa é utilizada para amenizar o sofrimento e refere-se a defesa psicológica que procura dar a experiência, comportamento ou pensamento uma justificativa lógica. A falta de escolaridade também é racionalizada e, no discurso, os sujeitos tentam justificar seus postos de trabalho.

Eu parei na $4^{a}$ série, na época, né? Tinha... A minha mãe sempre dizia "vai estudar, vai estudar...", e eu, sabe?, não tinha muita vontade de estudar e fiquei por aí, né? Aí, depois de uns anos que tava na empresa, aí... Na época que o Lula ganhou a primeira eleição, aí começaram que ele queria que o pessoal estudasse e tal, então começaram a pressionar um pouquinho, "ô, vamo voltar a estudar, tal, porque o pessoal, os novatos, tão vindo aí, tal, vocês têm que se mexer..." (A.). 
Nos relatos é possível analisar a utilização de outra estratégia defensiva: a negação dos riscos. Os trabalhadores falam, sem crítica alguma, sobre os riscos inerentes à atividade. Para Heloani e Lacman (2004), a banalização do risco e a negação do perigo no trabalho são estratégias utilizadas diante das situações de perigo.

Ah! Eu acho que, quando é pra ser, vai ser, ou tu soldando ou tu andando de carro, aí pode dar um acidente e... Ou, depende, tu trabalha num lugar limpinho e tudo, aí tu vai ter, sei lá... Não existe dizer. Eu acho que a vida é acreditar, até que vai, vamo embora... Depois para! (MC.).

Silva (2011) afirma que a negação dos riscos e a repressão do próprio medo constituem estratégias duradouras. Elas podem ser rompidas diante de diferentes ocorrências.

Veja bem, quando eu saio, eu sou um cara que me desligo da empresa. Me desligo! Se você me pergunta... Eu tô no ônibus e me perguntar "qual ferramenta você deixou na máquina?", bah, eu tenho que pensar, eu tenho que pensar, porque, assim, eu não sei se eu deixei essa ou aquela, porque - você pode perguntar até pra alguém em casa - é difícil eu comentar alguma coisa que acontece na empresa em casa. Porque, assim, se for coisa boa, eu comento... Se for coisa boa, tem que ficar sabendo, mas, se for coisa ruim, eu não preciso levar para casa coisa ruim... (C.).

As estratégias defensivas apresentam-se como necessárias para proteger a saúde mental dos efeitos do sofrimento, mas as mesmas estratégias que protegem podem se transformar em armadilhas contra o que faz o sujeito sofrer (Dejours, 2007). A partir da expressão utilizada por MC. - "trabalho é trabalho" -, observa-se como as estratégias podem se transformar em armadilhas subjetivas.

Trabalho é trabalho - quando tem que fazer, tem que fazer. E eu não escolho, sabe? Claro, tem coisas que você gosta um pouco menos, outras que você gosta mais, mas, infelizmente, depende do serviço (MC.).

Dejours (1992) afirma que o sofrimento não é explorado pela organização do trabalho, mas que as estratégias utilizadas para mediar esse sofrimento o são. As estratégias são importantes recursos para o equilíbrio psíquico dos trabalhadores e estão presentes em inúmeras situações. $\mathrm{Na}$ fala dos participantes deste estudo, as estratégias defensivas têm atuado na adaptação dos trabalhadores aos fatores geradores de sofrimento, risco e adoecimento.

\section{“Eu me sinto satisfeito, eu me sinto assim!": vivências de prazer}

O principal sentido do trabalho é o prazer que surge quando ele permite que o trabalhador se torne o sujeito da ação. A Psicodinâmica do Trabalho entende que as vivências de prazer podem existir mesmo em condições precarizadas, isso sendo possível no momento em que a organização do trabalho possibilita a mobilização de inteligência prática e espaços coletivos de discussão e de cooperação (Mendes, 2007).

Apesar de frágeis, as vivências de prazer relatadas pelos trabalhadores entrevistados basearamse, predominantemente, na satisfação em realizar as atividades de trabalho. É interessante pontuar a comparação que $\mathrm{R}$ faz com sua prática - é como se todo o assujeitamento que ocorre a partir da organização do trabalho pudesse ser explicado por meio do resultado da realização da tarefa. Encontrar o prazer no trabalho, da mesma forma como o sofrimento, também é experiência 
subjetiva. Ao produzir, o trabalhador sente-se estruturado como pessoa por ser valorizado e reconhecido (Mendes, 2007).

Olha, eu... É... Eu me sinto bem, porque eu gosto de fazer aquilo que eu faço lá, é gratificante você trabalhar, por exemplo... Como é que tu vai se sentir numa fábrica que, digamos, faz arma? Aí, lá você vê na TV: "fulano morre com um tiro", né?, aí, de repente, você fabricou aquela arma - como é que você vai se sentir? Agora, a gente fazendo uma panela, que tá fazendo, que vai ajudar a fazer uma comida... É gratificante pra gente fazer isso, né?, então eu me sinto assim, me sinto gratificante em fazer, porque é uma coisa que eu sei que vai pra cozinha de alguém. Que alguém vai fazer uma coisa boa e eu gosto de fazer aquilo que eu faço lá, lida com máquinas, enfim, né?, tem opções na vida, né?, então eu optei por isso aí e arregacei as mangas e vamo embora! (risos) (R.).

A mobilização subjetiva é um movimento do sujeito que viabiliza as capacidades de sentir, pensar e inventar para realizar um trabalho (Ferreira, 2009). Observam-se vivências de prazer nos momentos em que os trabalhadores conseguem ressignificar o sofrimento. $O$ reconhecimento é mais uma vivência de prazer. A valorização de um esforço possibilita ao sujeito encontrar realização em si mesmo através de seu trabalho (Mendes, 2007). Por meio do reconhecimento os sujeitos podem se transformar, e essa transformação ocorre através do olhar do outro e também do olhar da sociedade, dirigido a alguém que progride e realiza (Merlo, 2013).

Há 28 anos que eu trabalho com prensa. Então eu acho, assim, que isso é muito importante, essa função que eu faço, e conheço bastante o trabalho de prensa e dava até curso por fora, no sábado de manhã e... Adoro isso! Adoro isso! Gosto de fazer isso. Eu me sinto satisfeito, eu me sinto assim (C.).

Outro elemento importante nas relações de prazer é a criatividade, que possibilita que os trabalhadores imprimam sua marca pessoal no fazer laboral. Segundo Dejours (2007), na base da criatividade encontra-se a sublimação, que está diretamente relacionada ao sentido que o indivíduo confere às suas ações e à sua condição de trabalhador.

E isso era o lado bom... Várias vezes... Uma vez fizemos uma lixadeira lá, foi quase tudo eu que fiz as peças e foi muito legal! Mas aprendi bastante e deram bastante oportunidade (...). Ah! Eu gostava de, como diz o ditado, pôr a mão na massa mesmo, fazer as coisas, não deixar os outros fazer ou pegar, só quando tá, assim... Eu gosto de fazer as peças, né? (...) E, pelo menos, eu aprendi um pouco de tudo... (MX.).

Não se comentam amizades nas empresas - os sujeitos referem-se somente às relações de trabalho -, mas, em algumas situações, as relações estabelecidas nas empresas acabam indo além disso. A convivência e a troca entre as pessoas também são motivos que causam prazer nos trabalhadores. Mateus (MT.) comenta que existe, no meio da produção, um quadro que cada trabalhador preenche com carinhas que indicam seu humor diário. Esse espaço também tem por objetivo servir como ferramenta de consulta rápida para que o coordenador identifique diariamente presenças e ausências de cada profissional. Observando a fala de Mateus, é possível perceber que os trabalhadores utilizam esse recurso como meio de comunicação com a liderança, pois, quando é indicado humor triste, os trabalhadores são chamados para conversar.

Aí, tem o quadro de presença, aí, nesse quadro de presença, tem as cores lá... Verde, amarelo, laranja, vermelho e o cinza, se não me engano. O verde é "tu tá presente e tá bem", o amarelo é "tu tá presente e tá meia-boca”... E tem o presente e vermelho, que tu tá ruim. Aí, isso é uma maneira de o supervisor ver como é que tá. Uns colocavam pra ir lá, achavam que era uma forma de tu pedir um aumento 
pra liderança, pro supervisor. Daí eles iam lá, “ah, não tô ruim, eu quero um aumento...”, já vi vários casos e... Só. Mas é tranquilo, lá, o ambiente (MT.).

Esse movimento ao qual Mateus se refere representa uma das poucas estratégias de resistência e enfrentamento dos trabalhadores diante do controle e do discurso da organização do trabalho. Apesar de terem sido identificadas vivências de prazer, elas ainda precisariam ser potencializadas para realmente atuar na promoção da saúde. Como as vivências de sofrimento e a falta de espaços coletivos de fala são predominantes, as vivências de prazer tornam-se fragilizadas.

\section{As possibilidades de transformação e o papel da Psicologia}

Na clínica do trabalho, o maior desafio é o de contribuir para o fortalecimento dos sujeitos, potencializando a modificação dos contextos de trabalho - ou seja, em vez de realizar análise fatalista, adapta-se ao cenário vivenciado pelo trabalhador (Périlleux, 2013). As transformações do mundo do trabalho, por meio da lógica capitalista, têm evidenciado possível fragilidade entre o ser humano e seu trabalho. Com discurso humanizado, as organizações vão envolvendo os trabalhadores através de mecanismos de controle e manipulação que fragmentam a subjetividade do indivíduo (Faria, \& Meneghetti, 2007). O que permeou os discursos dos participantes deste estudo foi a naturalização de todas as características da organização do trabalho; além disso, observou-se que os trabalhadores não percebem possibilidades de transformação em seus trabalhos.

Percebe-se que a Psicologia, através das práticas de recursos humanos, pode contribuir tanto com a submissão e com o adoecimento, como com a promoção da saúde e da autonomia dos trabalhadores. Práticas como treinamentos prontos, sem espaços de fala e escuta, planos de metas e resultados atrelados aos salários e às políticas de desligamentos e planos de cargos e salários, que promovem a individualização e a quebra do coletivo, são exemplos que podem contribuir com o adoecimento. Por outro lado, o psicólogo, como agente de transformação e promoção da saúde, pode problematizar esses espaços, auxiliar as empresas no entendimento dos processos de saúde e adoecimento, atuando principalmente na (des)naturalização de alguns modos de trabalho. Além disso, é fundamental oferecer espaços de fala e escuta, assim como o oferecido na coleta de dados desta pesquisa. Da mesma forma, os sindicatos das categorias e as organizações coletivas de trabalhadores devem ser informados e sensibilizados por meio dos dados coletados para que possam garantir os direitos dos trabalhadores e ampliar a legislação existente e as políticas públicas vigentes.

Entende-se que, quando o sofrimento do trabalhador passa a ser escutado, compreendido, interpretado, elaborado e perlaborado em espaços públicos, surge a possibilidade de reconstrução dos espaços subjetivos e também de fortalecimento do coletivo de trabalho, abrindo-se, então, espaço para que os próprios trabalhadores possam se organizar e mobilizar para a transformação da organização do trabalho. Dessa forma, falar sobre o sofrimento resgata no trabalhador o processo de pensar sobre o trabalho, colocando-o como sujeito da ação (Mendes, 2007). Outros estudos precisam ser realizados, pois, nesta pesquisa, observou-se que os trabalhadores tiveram a possibilidade de refletir sobre seus trabalhos e pensar em novas formas de encontrar sentido(s) para ele.

\section{Considerações finais}

Para analisar as vivências de trabalho de trabalhadores inseridos na indústria metalmecânica e compreender as vivências de prazer e sofrimento e as estratégias defensivas utilizadas por esses 
trabalhadores diante do sofrimento, este estudo ampliou os dados já existentes acerca dos riscos físicos atrelados à atividade e evidenciou problemáticas relacionadas à organização do trabalho nesse contexto. Nesse sentindo, a análise das vivências desses trabalhadores atribuiu visibilidade para o intenso processo de sofrimento e o grande risco de adoecimento dos entrevistados, evidenciando a necessidade de problematizar e repensar as relações e a configuração do trabalho metalmecânico.

A partir dos pressupostos da Psicodinâmica do Trabalho, o pesquisador precisou mobilizar os trabalhadores para que eles falassem sobre vivências de trabalho, o que inspirou o nome do artigo. Sobre as vivências de sofrimento, houve relatos de pressão, cobrança, falta de valorização financeira e imposição de rotinas do trabalho, diante das quais os trabalhadores desenvolvem estratégias defensivas pautadas na sua adaptação aos fatores geradores de sofrimento, risco e adoecimento. As vivências de prazer puderam ser observadas na satisfação de todos os trabalhadores em efetivar seu trabalho. A partir dos momentos de reconhecimento, o trabalho passa a ser significado, o que possibilita que os sujeitos realizem a si mesmos através dele, criando espaços para a criatividade emergir, através da convivência com os colegas de trabalho.

O papel da Psicologia, nesse contexto, é de extrema importância, pois, quando o sofrimento do trabalhador passa a ser escutado, compreendido, interpretado e elaborado, surge a possibilidade de reconstruir espaços subjetivos e fortalecer os coletivos de trabalho, para que os próprios trabalhadores possam se organizar e mobilizar para a transformação da organização do trabalho.

\section{Referências}

Alves, G. A. P. (2008). A subjetividade às avessas: toyotismo e "captura" da subjetividade do trabalho pelo capital. Cadernos de Psicologia Social do Trabalho, 11 (2), 223-239.

Antunes, R. (2005). Os sentidos do trabalho: ensaio sobre a afirmação e a negação do trabalho (Coleção Mundo do Trabalho). (7a ed.). São Paulo: Boitempo.

Bardin, L. (2011). Análise de conteúdo. São Paulo: Edições 70.

Biernacki, P., \& Waldorf, D. (1981). Snowball sampling: problems and techniques of chain referral sampling. Sociological Methods EO Research, 10 (2), 141-163.

Conselho Federal de Psicologia. (2000). Resolução 016/2000. Recuperado de http://www.crpsp.org.br/portal/orientacao/ resolucoes_cfp/fr_cfp_016-00.aspx [9 dezembro 2016]

Dejours, C. (1992). A loucura do trabalho: estudo de psicopatologia do trabalho. (5a ed. ampl.). São Paulo: Cortez.

Dejours, C. (2004a). Da psicopatologia à psicodinâmica do trabalho. Rio de Janeiro: Fiocruz.

Dejours, C. (2004b). Subjetividade, trabalho e ação. Produção, 14 (3), 27-34.

Dejours, C. (2007). A banalização da injustiça social. (7a ed.). Rio de Janeiro: Fundação Getúlio Vargas.

Dejours, C. (2011). A carga psíquica do trabalho. In C. Dejours, E. Abdoucheli, \& C. Jayet (Orgs.), Psicodinâmica do trabalho: contribuições da escola dejouriana na análise da relação prazer, sofrimento e trabalho (pp. 21-32). São Paulo: Atlas.

Dejours, C., \& Abdoucheli, E. (2011). Itinerário teórico em psicopatologia do trabalho. In C. Dejours, E. Abdoucheli, \& C. Jayet (Orgs.), Psicodinâmica do trabalho: contribuições da escola dejouriana na análise da relação prazer, sofrimento e trabalho (pp.119-141. São Paulo: Atlas.

Faria, J. H., \& Meneghetti, F. K. (2007). O sequestro da subjetividade. In J. H. Faria (Org.), Análise critica das teorias e práticas organizacionais (pp. 45-67). São Paulo: Atlas.

Ferreira, J. B. (2009). Perdi um jeito de sorrir que eu tinha: violência, assédio moral e servidão voluntária no trabalho. Rio de Janeiro: 7 Letras.

Gil, A. C. (2010). Como elaborar projetos de pesquisa. (5a ed.). São Paulo: Atlas.

Gonçalves, C. G. O., \& Dias, A. (2011). Três anos de acidentes do trabalho em uma metalúrgica: caminhos para seu entendimento. Ciência $\mathcal{E}$ Saúde Coletiva, 16 (2), 635-646. 
Guaraná, N. B. (2006). Mesoeconomia e seu uso potencial na gestão tributária: o caso do complexo metalmecânico do Rio Grande do Sul. Dissertação de mestrado. Pontifícia Universidade Católica do Rio Grande do Sul, Porto Alegre.

Heloani, J. R., \& Lancman, S. (2004). Psicodinâmica do trabalho: o método clínico de intervenção e investigação. Produção, 14 (3), 77-86.

Herédia, V. B. M. (2007). Simecs: 50 anos. Caxias do Sul: Belas Artes.

Instituto Brasileiro de Geografia e Estatística (2014). Comparação entre os municípios do Rio Grande do Sul. Recuperado de http://cidades.ibge.gov.br/comparamun/compara.php?Lang=\&lista=uf\& coduf=43\&idtema=119\& codv=V01 [9 dezembro 2016]

Martins, S. R. (2012). A clínica do trabalho (Coleção Clínica Psicanalítica). São Paulo: Casa do Psicólogo.

Mendes, A. M. (2007). Novas formas de organização do trabalho, ação dos trabalhadores e patologias sociais. In A. M. Mendes (Org.), Psicodinâmica do trabalho: teoria, método e pesquisas (pp. 49-62). (Coleção Trabalho Humano). São Paulo: Casa do Psicólogo.

Mendes, A. M., \& Morrone, C. (2010). Trajetória teórica e pesquisas brasileiras sobre prazer e sofrimento no trabalho. In A. M. Mendes, A. R. C. Merlo, C. F. Morrone, \& E. P. Facas (Orgs.), Psicodinâmica e clinica do trabalho: temas, interfaces e casos brasileiros (pp.29-52). Curitiba: Juruá.

Mendes, A. M. \& Merlo, Á. R. C. (2009). Perspectivas do uso da psicodinâmica do trabalho no Brasil: teoria, pesquisa e ação. Cadernos de Psicologia Social do Trabalho, 12 (2), 141-156.

Merlo, Á. R. C. (2013). Sofrimento silenciado, patologia da solidão e suicídio no trabalho: a questão da atenção à saúde. In Á. R. C. Merlo, A. M. Mendes, \& R. D. Moraes (Orgs.), O sujeito no trabalho: entre a saúde e a patologia (pp. 93. 99). Curitiba: Juruá.

Ministério da Saúde (1996). Resolução nº 196/96. Brasília: Ministério da Saúde. Recuperado de http://conselho.saude. gov.br/resolucoes/reso_96.htm [13 janeiro 2017]

Ministério do Trabalho e Emprego (2014). Análise mensal do mercado de trabalho. Recuperado de http://www3.mte.gov.br/ geral/estatisticas.asp [13 de janeiro de 2017]

Ministério do Trabalho e Emprego (2014). Anuário estatístico de metalurgia. Recuperado de http://www.mme.gov.br/ documents/10584/1865251/Anuario_Setor_Metalurgico_2014_base_2013.pdf/136ee218-8fb3-430d-97dc2e9171c6a0e8 [13 de janeiro de 2017]

Ministério do Trabalho e Emprego (2014). Bases estatísticas RAIS e CAGED. Recuperado de http://bi.mte.gov.br/bgcaged/ login.php [9 dezembro 2016]

Ministério do Trabalho e Emprego (2014). Normas regulamentadoras. Recuperado de http://trabalho.gov.br/index.php/ seguranca-e-saude-no-trabalho/normatizacao/normas-regulamentadoras [13 de janeiro de 2017]

Ministério do Trabalho e Emprego. (2014). 1 Boletim Quadrimestral de Benefícios por Incapacidade. Recuperado de http:// www.previdencia.gov.br/wp-content/uploads/2014/04/I-Boletim-Quadrimestral-de-Benef\%C3\%adcios-porIncapacidade1.pdf [9 dezembro 2016]

Périlleux, T. (2013). O trabalho e os destinos políticos do sofrimento. In Á. R. C. Merlo, A. M. Mendes, \& R. D. Moraes (Orgs.), O sujeito no trabalho: entre a saúde e a patologia (pp. 73-92). Curitiba: Juruá.

Picoloto, D., \& Silveira, E. (2008). Prevalência de sintomas osteomusculares e fatores associados em trabalhadores de uma indústria metalúrgica de Canoas - RS. Ciência Ë Saúde Coletiva, 13 (2), 507-516.

Silva, E. S. (2011). Trabalho e desgaste mental: o direito de ser dono de si mesmo. São Paulo: Cortez.

Uchida, S. (2007). Organização do trabalho: vivências de sofrimento e prazer. In A. M. Mendes, S. C. Cruz, \& E. P. Facas (Orgs.), Diálogos em psicodinâmica do trabalho (pp. 105-117). Brasília: Paralelo 15.

\section{Endereço para correspondência} maristelarancan.psi@gmail.com, carmemgiongo@feevale.br
Recebido em: 21/04/2015

Revisado em: 27/04/2016 Aprovado em: 03/12/2016 